\title{
Analyzing the effect of c-Myc oncogene and matrix mettalloproteinase- 2 enzyme expression on metastasis and prognosis of malignant melanoma
}

\author{
Abdulcebbar Siyer ${ }^{1}$, Yasemin Yuyucu Karabulut ${ }^{2}$, Şakir Ünal ${ }^{1}$, Didem Derici ${ }^{3}$
}

${ }^{1}$ Mersin Üniversitesi Tip Fakültesi, Plastik ve Rekonstriktif Cerrahi, Mersin, Türkiye

${ }^{2}$ Mersin Üniversitesi Tip Fakültesi, Patoloji, Mersin, Türkiye

${ }^{3}$ Mersin Üniversitesi Tip Fakültesi, Biyoistatistik, Mersin, Türkiye
Correspondence: Dr. Yasemin Yuyucu Karabulut, Mersin Üniversitesi Tip Fakültesi, Patoloji ABD, Mersin, Türkiye E-mail: yykarabulut@yahoo.com.tr
Received: 18 February 2016,

Accepted: 27 June 2016

DOI: $10.5799 /$ jcei. 328612

\section{INTRODUCTION}

Malign melanoma develops as a result of the malign transformation of the melanocytes, which produce body pigments. It may be encountered in any of body locations, where melanocytes are available, including skin, eye and the mucous membranes of the upper gastrointestinal tract, sinuses, anus, and vagina. Melanoma emerges most commonly in the skin. Although, only $5 \%$ of all skin cancers are melanomas, it is responsible for yearly 50.000 deaths worldwide [1]. An increase in its incidence was observed in last years. The proposed reasons for this increase are the detection of the lesions in the early phase and increased exposure to sunlight (UV) [2]. Early diagnosis of the lesions enabled an increase of 5-year survival rate from $82 \%$ up to $91 \%$ in last 20 years [3].

Chemotherapy and therapy with biological agents do not provide successful results in metastatic patients [2]. In recent studies, it was found out that mutated genes like BRAF and KIT were important regarding the treatment and along with the development of the targeted molecules new treatment regimens for metastatic melanoma were introduced [2-4].

In some recent studies, several factors affecting the prognosis negatively were reported. For example, it was confirmed that the presence of the ulceration, increased mitotic activity and increased serum LDH levels were negative indicators of the disease prognosis, and they are accepted as the criteria of the poor prognosis in the latest staging system. In this study, our objective was to evaluate the effect of the expression of the c-Myc oncogene and matrix metolloproteninase-2 [MMP2] on the metastasis and prognosis of the malign melanoma through the analysis of the biopsy materials. With this study, we also aimed to provide information about the progress and prognosis of the malign 
melanoma, which is a disease with limited treatment options, and so to propose a guide for the selection of therapy regimen and for the management of the disease.

\section{METHODS}

This study was conducted in our clinic after the approval of the ethics committee for clinical trials (Approval date 20.03.2014; Number: 2014/46). 63 patients, who were followed up in our clinic with the diagnosis of malign melanoma between the years 2006 and 2015, were included in our study. Through the screening of the archived biopsy materials and patient files, we recorded the age, gender, staging according to the invasion depth (Clark) and tumor thickness (Breslow), histological type, localization, BRAF and c-KIT mutations, follow-up and survival rates of the enrolled patients.

Breslow classification is divided into 4 stages:

Stage 1: depth less than $0.76 \mathrm{~mm}$

Stage 2: depth between $0.76 \mathrm{~mm}-1.50 \mathrm{~mm}$

Stage 3: depth between $1.51 \mathrm{~mm}-4.00 \mathrm{~mm}$

Stage 4: depth greater than $4.00 \mathrm{~mm}$

\section{Clark classification:}

Level I - Atypical melanocytes confined to the epidermis (in situ melanoma).

Level II - Atypical melanocytes invaded the papillary dermis but not extended to the reticular dermis.

Level III - Atypical melanocytes filled the papillary dermis and extended to the reticular dermis, but not diffused in the reticular dermis.

Level IV - Atypical melanocytes invaded and filled the reticular dermis.

Level V - Atypical melanocytes invaded deeply subcutaneous tissue.

After the selection of the appropriate paraffin-embedded blocks, c-Myc oncogene and MMP2 enzyme expression were assessed.

For every patient, one diagnostic paraffin-embedded block (which contained maximum tumor tissue and minimum melanin pigment) was chosen, and sections with 3-micron thickness were cut for the immunohistochemical analysis of c-Myc (Clone 9E10.3, Thermo Scientific) and MMP2 (CA-4001/CA719E3C, Abcam). Sections were first deparaffinized and then antigen retrieval process was carried out in a solution prepared with ethylenediaminetetraacetic acid (EDTA) and citrate mixture. Afterward, in order to inhibit the endogenous peroxidase activity, the sections were first incubated in the $3 \%$ hydrogen peroxide solution for 20 minutes and then incubated with the primary antibody in the room temperature for 60 minutes. Thereafter, the sections placed in the streptavidin peroxidase for 10 minutes and then they were incubated in the DAB chromogen for 3-5 minutes. Finally, the sections were stained with Mayer hematoxylin for 1 minutes and covered with xylene-based coverslips after soaked in the xylene and alcohol derivatives. All procedure was carried out in a humid environment to prevent the tissues from drying out.

Immunohistochemical evaluation was performed with a magnification of $x 100$.

During the examination of the c-Myc immunohistochemical staining, not stained samples were evaluated as negative, and cytoplasmic staining was evaluated as positive [Figure 1a,1b]. For MMP2, cytoplasmic staining more than $5 \%$ of the tumor cells was considered as positive. In respect of MMP2 staining, tumors were classified as negative [cytoplasmic staining in less than $5 \%$ of tumor cells]; as positive [cytoplasmic staining in 5\% $-50 \%$ of tumor cells] and high positive [cytoplasmic staining in more than $50 \%$ of tumor cells] [Figure $2 \mathrm{a}, 2 \mathrm{~b}, 2 \mathrm{c}$ ].

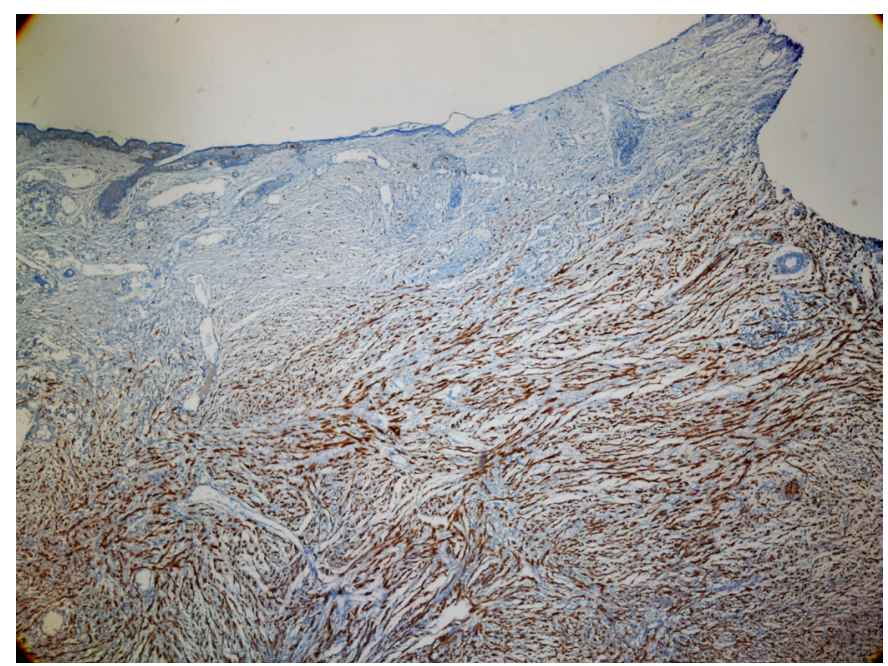

Figure 1a: Diffuse cytoplasmic c-Myc staining (c-Myc x 100), 1 b. (c-Myc x 200).

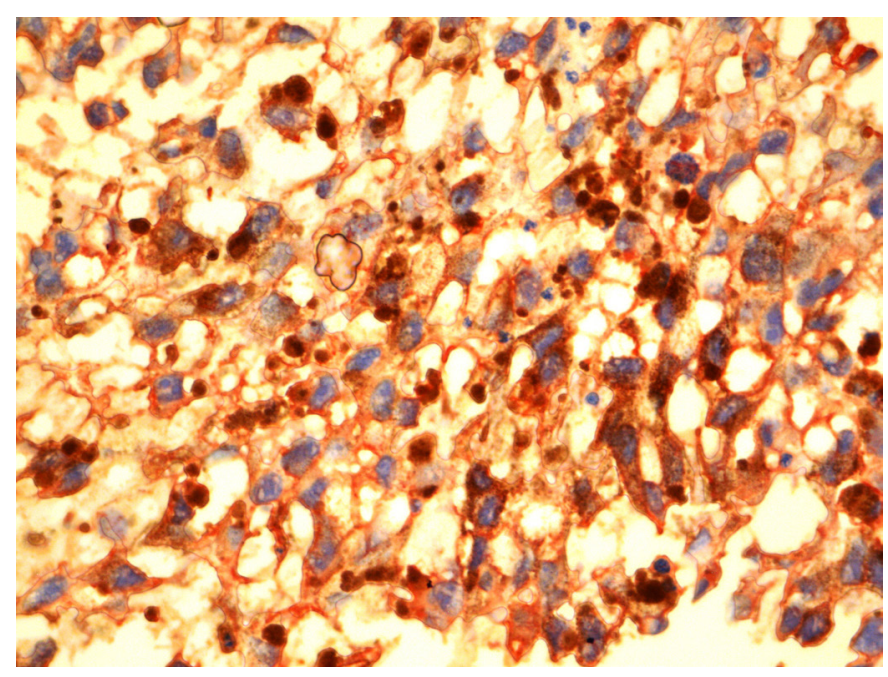

Figure 1b. Diffuse cytoplasmic c-Myc staining (cMyc x 200). 


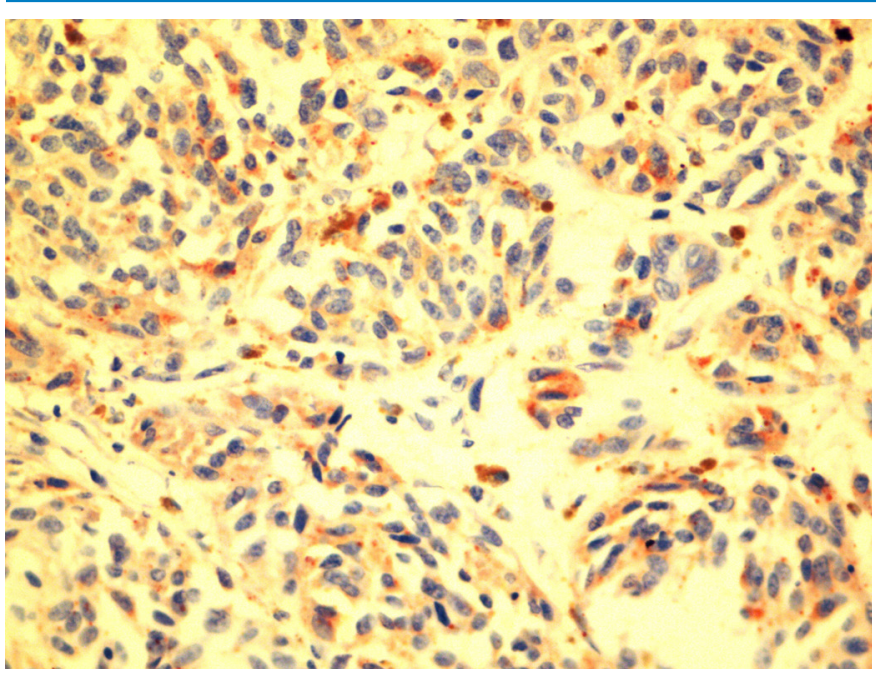

Figure 2a. MMP2 negative, cytoplasmic staining in less than $5 \%$ of the tumor cells (MMP2x100).

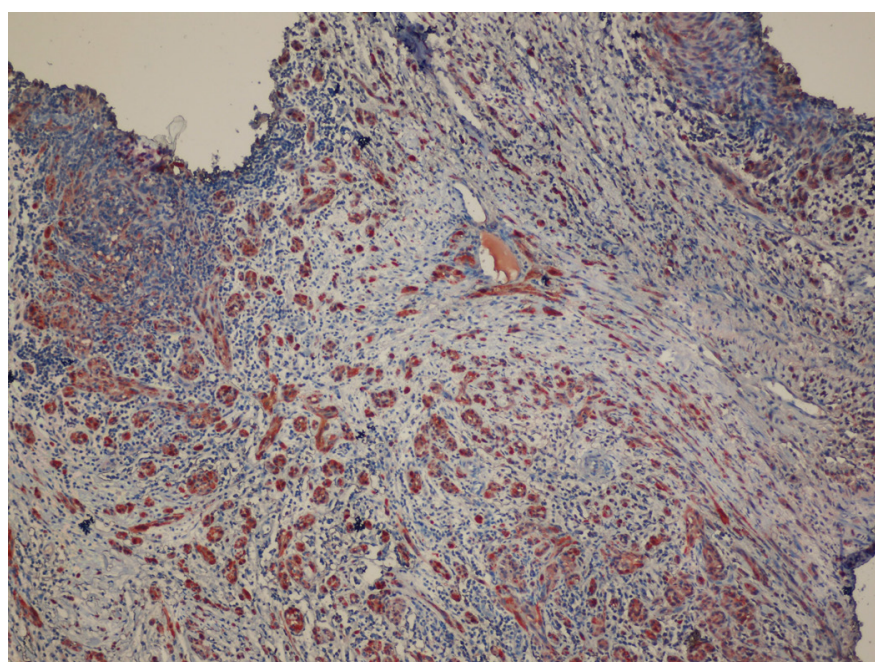

2b. MMP2 positive, cytoplasmic staining in $5 \%-50 \%$ of the tumor cells (MMP2x100).

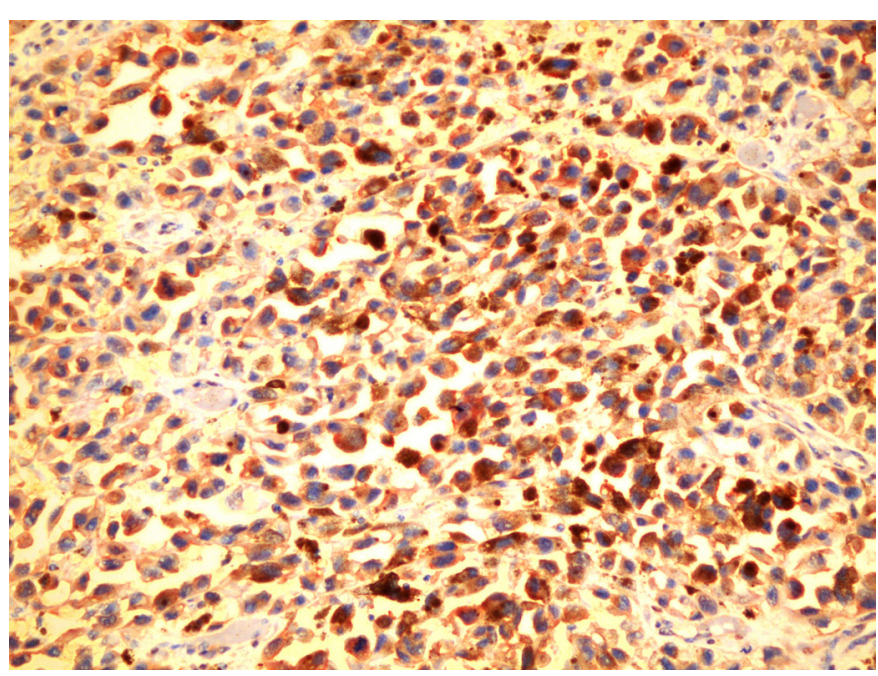

2c. MMP2 high positive, cytoplasmic staining in more than $50 \%$ of the tumor cells (MMP2x100).
During the mutational analyses of KIT and BRAF, Tumour cells were isolated from paraffin-embedded tissue (either primary tumour, lymph node metastases, skin metastases or local recurrences), if necessary by micrographic dissection using the PALM LaserMicroBeam System (PALM Wolfratshausen, Germany). DNA extraction was performed with the DNA extraction kit from Qiagen (Hilden, Germany) following the instructions of the manufacturer. To detect the BRAF V600E mutation a LightCycler fluorescence resonance energy transfer (FRET) assay with two fluorescent hybridisation probes was performed. Real-time PCR was performed by using LightCycler FastStart DNA Master HybProbe (Roche Diagnostics GmbH, Mannheim, Germany) All PCR products that showed deviation from the Wt (wild-type) genomic DNA melting peak as well as from the positive control samples were confirmed by direct sequencing of exon 15 of the BRAF gene (SequiServe, Vaterstetten, Germany).

\section{Statistical Analysis}

All results were recorded and computerized. The data were listed in MS-Excel format and analyzed by the department of biostatistics. Analyses were carried out with SPSS v.11.5 and MedCalc v.12.3.0. The accepted limit of significance was $p<0.05$. Chi-square test was used for the analysis of the cross-tables. As the distribution hypothesis was not obtained, Mann-Whitney $\mathrm{U}$ test was used for the comparison of two groups and KruskalWallis test for the comparison of more than two groups. In order to detect the origin of the difference, Dunn's test (posthoc test) was implemented. For the evaluation of the differences between the groups regarding the survival time, survival analysis was carried out, and the long-rank test was referred.

\section{RESULTS}

63 malign melanoma patients, who applied to our clinic, were enrolled into the study. 31 of them were females (49.2\%) and $32(50.8 \%)$ males. The average age was 67 years (20-89 years). In 13 patients tumor was localized in the upper extremity (21.7\%), in 27 patients in lower extremity (45.0\%), in 4 patients in the trunk (6.7\%) and in 16 patients in head and neck region (26.7\%).

Pathological examination revealed the following histomorphological types: superficial spreading melanoma $(n=21$; $39.6 \%)$, nodular melanoma ( $\mathrm{n}=21 ; 39.6 \%)$, acral lentiginous melanoma $(n=7 ; 13.2 \%)$, subungual melanoma $(n=3 ; 5.7 \%)$, lentigo maligna melanoma $(n=1 ; 1.9 \%)$. In 10 patients the melanoma type could not be identified.

Staging of the patients according to the Breslow and Clark systems:

Breslow system: 6 patients were in Stage 1 (12.5\%), 5 patients in Stage 2 (10.4\%), 13 patients in Stage 3 (27.1\%), 24 patients in Stage $4(50 \%)$.

Clark system: 8 patients were in Level II (16.3\%), 6 patients in Level III (12.2\%), 12 patients in Level IV (42.9\%) and 14 patients in Level V (28.6\%). 
8 patients were evaluated for BRAF mutation. C-KIT mutation analysis, which was carried out for 2 patients, displayed negative results.

In our study, 47 (74\%) of the biopsy materials had sufficient tumor size for the immunohistochemical examination. 23 of these 47 samples had metastatic tumors. We detected metastasis overall in 48 of the 63 patients.

The correlation of the immunohistochemical evaluation of the MMP2 and c-Myc with the prognostic parameters was summarized in Tables 1-4. Hereunder: There was no significant difference between the negative and positive c-Myc cases regarding the survival rate $(\mathrm{p}=0.069)$. In metastatic cases, 18 patients $(78 \%)$ were c-Myc positive and 5 patients (21\%) c-Myc negative. However, no significant difference was detected between the c-Myc and metastasis ( $\mathrm{p}=1.000)$. Positive staining for MMP2 was encountered in 10 patients $(21 \%)$ and negative staining in 8 patients $(17 \%)$ and intensive staining in 29 patients (61\%). In metastatic cases (among 47 investigated patients), MMP2 staining was considered as positive in 5 patients $(21 \%)$, negative in 5 patients $(21 \%)$ and high positive in 13 patients (56\%).

There was no statistically significant correlation between the MMP2 and metastasis ( $\mathrm{p}=0.999)$. However, as it was previously demonstrated that both of these parameters decreased the survival rate, it was suggested that they also pointed at an increased risk of invasion or metastasis and had a negative influence on the course of the disease.

Table 1. MMP2- prognostic parameters

\begin{tabular}{|c|c|c|c|c|c|c|c|c|c|c|c|c|c|}
\hline \multirow{2}{*}{ MMP-2 } & \multirow[t]{2}{*}{$\begin{array}{c}\text { Age } \\
\text { (year) }\end{array}$} & \multirow[t]{2}{*}{$\begin{array}{l}\text { Sex } \\
F / M\end{array}$} & \multicolumn{4}{|c|}{$\begin{array}{c}\text { Clark score } \\
\text { n (\%) }\end{array}$} & \multicolumn{4}{|c|}{$\begin{array}{c}\text { Breslow score } \\
\mathrm{n}(\%) \\
\end{array}$} & \multirow[t]{2}{*}{ Metastasis } & \multirow[t]{2}{*}{$\begin{array}{l}\text { Live/ } \\
\text { Dead }\end{array}$} & \multirow[t]{2}{*}{$\begin{array}{c}\text { Follow-up } \\
\text { (month) }\end{array}$} \\
\hline & & & 2 & 3 & 4 & 5 & 1 & 2 & 3 & 4 & & & \\
\hline Positive & $\begin{array}{c}64.5 \\
(45-84)\end{array}$ & $6 / 4$ & $\begin{array}{c}2 \\
(40)\end{array}$ & $\begin{array}{c}2 \\
(40)\end{array}$ & $\begin{array}{c}4 \\
(25)\end{array}$ & $\begin{array}{c}2 \\
(15.4)\end{array}$ & $\begin{array}{c}0 \\
(0)\end{array}$ & $\begin{array}{c}1 \\
(50)\end{array}$ & $\begin{array}{c}4 \\
(36.4)\end{array}$ & $\begin{array}{c}5 \\
(22.7)\end{array}$ & $5(21.7)$ & $3 / 7$ & $46(15-75)$ \\
\hline Negative & $\begin{array}{c}59.5 \\
(20-73)\end{array}$ & $3 / 5$ & $\begin{array}{c}3 \\
(60)\end{array}$ & $\begin{array}{c}0 \\
(0)\end{array}$ & $\begin{array}{c}2 \\
(12.5)\end{array}$ & $\begin{array}{c}3 \\
(23.1)\end{array}$ & $\begin{array}{c}2 \\
(66.7)\end{array}$ & $\begin{array}{c}0 \\
(0)\end{array}$ & $\begin{array}{c}2 \\
(18.2)\end{array}$ & $\begin{array}{c}3 \\
(13.6)\end{array}$ & $5(21.7)$ & $2 / 6$ & $69.5(27-84)$ \\
\hline$P$ value & 0.120 & 0.631 & & & .057 & & & & 372 & & 0.999 & 0.066 & 0.005 \\
\hline
\end{tabular}

Table 2. MMP2, histological type and localization

\begin{tabular}{|c|c|c|c|c|c|c|c|c|}
\hline \multirow[t]{2}{*}{ MMP-2 } & \multicolumn{4}{|c|}{$\begin{array}{c}\text { Localization } \\
\text { n (\%) }\end{array}$} & \multicolumn{4}{|c|}{$\begin{array}{c}\text { Histological Type } \\
\text { n (\%) }\end{array}$} \\
\hline & Head-Neck & Upper Extr & Lower Extr & Trunk & Sperficial & Nodular & Acral & Subungal \\
\hline Positive & $1(8.3)$ & 1 (11.1) & $8(36.4)$ & $0(0)$ & $6(37.5)$ & $2(10.5)$ & $0(0)$ & $0(0)$ \\
\hline$P$ value & \multicolumn{4}{|c|}{0.235} & \multicolumn{4}{|c|}{0.131} \\
\hline
\end{tabular}

Extr: Extremity

Table 3. C- myc, prognostic parameters

\begin{tabular}{|c|c|c|c|c|c|c|c|c|c|c|c|c|c|}
\hline \multirow[t]{2}{*}{ C myc } & \multirow[t]{2}{*}{$\begin{array}{c}\text { Age } \\
\text { (year) }\end{array}$} & \multirow[t]{2}{*}{$\begin{array}{l}\text { Sex } \\
\text { F/M }\end{array}$} & \multicolumn{4}{|c|}{$\begin{array}{c}\text { Clark score } \\
\text { n (\%) }\end{array}$} & \multicolumn{4}{|c|}{$\begin{array}{c}\text { Breslow score } \\
\text { n (\%) }\end{array}$} & \multirow{2}{*}{$\begin{array}{c}\text { Metastasis } \\
3\end{array}$} & \multirow{2}{*}{$\begin{array}{c}\text { Live/ } \\
\text { Dead }\end{array}$} & \multirow{2}{*}{$\begin{array}{c}\begin{array}{c}\text { Follow-up } \\
\text { (month) }\end{array} \\
5\end{array}$} \\
\hline & & & 2 & 3 & 4 & 5 & 1 & 2 & 3 & 2 & & & \\
\hline $\begin{array}{l}\text { Negative } \\
(n=10)\end{array}$ & $\begin{array}{c}58.5 \\
{[20-73)}\end{array}$ & $5 / 5$ & $\begin{array}{c}4 \\
(80)\end{array}$ & $\begin{array}{c}0 \\
(0)\end{array}$ & $\begin{array}{c}3 \\
(18.8)\end{array}$ & $\begin{array}{c}2 \\
(15.4)\end{array}$ & $\begin{array}{c}2 \\
(66.7)\end{array}$ & $\begin{array}{c}0 \\
(0)\end{array}$ & $\begin{array}{c}4 \\
(36.4)\end{array}$ & $\begin{array}{c}2 \\
(9.1)\end{array}$ & $5(21.7)$ & $3 / 7$ & $68(24-80)$ \\
\hline$P$ value & 0.024 & 1.000 & & & & & & 0.0 & & & 1.000 & 0.286 & 0.005 \\
\hline
\end{tabular}


Siyer A, et al. c-Myc oncogene and matrix mettalloproteinase-2 enzyme expression in malignant melanoma

Table 4. C- myc, Histological type, localization

\begin{tabular}{|c|c|c|c|c|c|c|c|c|}
\hline \multirow[t]{2}{*}{ C-myc } & \multicolumn{4}{|c|}{$\begin{array}{l}\text { Localization } \\
\text { n (\%) }\end{array}$} & \multicolumn{4}{|c|}{$\begin{array}{c}\text { Histological Type } \\
\text { n (\%) }\end{array}$} \\
\hline & Head-Neck & Upper Extr & Head-Neck & Upper Extr & Head-Neck & Upper Extr & Head-Neck & Upper Extr \\
\hline Pozitive & $9(75)$ & $8(88.9)$ & $19(86.4)$ & $1(50)$ & $13(81.3)$ & 14 (73.7) & $4(100)$ & $2(80.5)$ \\
\hline Negative & $3(25)$ & 1 (11.1) & $3(13.6)$ & $1(50)$ & $3(18.8)$ & $5(26.3)$ & $0(0)$ & $0(0)$ \\
\hline
\end{tabular}

Extr: Extremity

\section{DISCUSSION}

Malign melanoma which has a continuously increasing incidence in last years, is a disease with a poor prognosis due to aggressive progress in the metastatic cases. In recent years, several studies were conducted to obtain information about the clinical course of the disease, to identify the right therapeutic regimen and the new prognostic factors in order to improve the management of the disease. Immunohistochemical studies showed that oncogenes and tumor suppressing genes like KI67, p53, and c-Myc, metalloproteinases, and molecules like MCAM with suspected role on invasion might be indicators of the poor prognosis.

It was suggested that the matrix metalloproteinases, which belonged to the zinc-based endopeptidase group, had a role in the tumor invasion and metastasis as a result of their destructive activity on the extracellular matrix. MMP2 and MMP9 belong to the subgroups of the gelatinase enzymes. In the literature, there are studies showing the correlation of the gelatinase enzymes expression with the tumor stage and the poor prognosis [7].

The formation mechanism of the cancer cells depends on the oncogene mutations or on the deterioration of the balance between the cell apoptosis and cell proliferation as a consequence of the damage to the tumor suppressive genes due to the mutations or changes in the oncogenes. In this context, the damage to c-Myc oncogene might trigger the cell proliferation or transformation. Regarding the literature, in some studies, a correlation between the c-Myc oncogene expression and poor prognosis was reported $[8,9]$.

In our study, the c-Myc oncogene and MMP2 enzyme positivity supported their decreasing effect on the survival rates of the patients. Ramsden et al. evaluated c-Myc oncogene expression in 117 patients with malign melanoma and divided the patients into two groups in respect of being below or above the mean value of the c-Myc positivity. The results showed that the group with high c-Myc positivity had a significantly poorer prognosis [10]. The 5-year survival rates in the patients with low and high c-Myc positivity were $80.8 \%$ and $62.8 \%$ respectively. The investigators concluded that c-Myc should be considered as a prognostic factor and should be examined routinely for the diagnosis period of the disease. In our study, the comparison of the c-Myc and follow- up duration revealed that c-Myc positivity decreased significantly the survival rate.

Vaisanen et al. investigated 157 melanoma patients for MMP2 and MMP9 enzyme expression and showed that MMP2 decreased significantly the survival rate [11]. In this study, investigators suggested that the overexpression of MMP2 might be an independent prognostic factor of the melanoma-related mortality and demonstrated that the mortality risk was increased 2.6-fold. However, no correlation for MMP9 was determined [11]. In our study, we had a similar result in the survival analysis and observed that especially high positivity of MMP2 decreased significantly the survival rate.

Ross et al. investigated 67 melanoma patients for c-Myc overexpression and $\mathrm{p} 53$ positivity in respect of the survival rate. In this study, it was demonstrated that high c-Myc + low p53 levels decreased the 5-year survival rate down to $25 \%[\mathrm{p}=0.038]$ [12]. In conclusion, they stated that c-Myc increased our understanding of the survival rates and therapeutic strategies targeted to c-Myc might slow down the growth rate of the tumor in melanoma patients.

In the study conducted by Vaisanen et al., they observed that concomitant overexpression of MMP2 and Ki67 decreased the 5 -year survival and might be an indicator of the poor prognosis. 5-year survival was 50\% in patients with MMP2 and Ki67 overexpression and 88\% in patients with low MMP2 and Ki67 levels. They also inspected that mortality risk was increased 5.6fold [9].

In our study group, most of the patients were in advanced stages. Although, the most commonly reported type was superficial spreading melanoma in the literature [2-6], in our study group the number of superficial spreading and nodular malign melanoma cases were equal. The developments about the determination of the melanoma characteristics in molecular level play an important role in the development of the mutant BRAF protein inhibitors. Chapman et al. showed in their study that vemurafenib - a BRAF inhibitor - increased the survival rate [13]. We detected in 8 of our patients BRAF gene mutation and these patients were treated with vemurafenib in our oncology department.

In our study, we observed that c-Myc and MMP2 positivity along with MMP decreased the follow-up durations and increased 
the mortality significantly. We determined that both of these parameters were more common in metastatic patients compared with the non-metastatic patients. In conclusion, we believe that like the prognostic factors such as the depth of the tumor, number of mitoses, ulceration, lymphatic response, which affect the survival rate, also presence c-Myc and MMP2 might be considered as one of the criteria used for staging. In this context, they might be a guiding tool for the management of the disease and would be directive for the future studies, which would be conducted for the determination of the new prognostic factors.

Declaration of conflicting interests: The authors declare that they have no conflict of interest.

Financial Disclosure: No financial support was received.

\section{REFERENCES}

1. Ferlay J, Shin HR, Bray F, et al. Estimates of worldwide burden of cancer in 2008: GLOBOCAN 2008. Int J Cancer. 2010;127:2893-917.

2. Linos E, Swetter SM, Cockburn MG, et al. Increasing burden of melanoma in the United States. J Invest Dermatol. 2009;129:1666-74.

3. Siegel R, Zou Z, Jemal A, et al. Cancer Statistics, 2014. CA: A Cancer J Clinician. 2014;64:9-29.

4. Lotze MT. Keystone symposium: Melanoma and the biology of the neural crest. Melanoma Res. 1992;2:131.
5. Erdmann F, Lortet,Tieulent J, Schüz J, et al. International trends in the incidence of malignant melanoma 1953-2008-are recent generations at higher or lower risk? Int J Cancer. 2013;132:385-400.

6. American Cancer Society, American Cancer Society facts and figures. American Cancer Society, Atlanta, 1998.

7. Turpeenniemi-Hujanen, T: Gelatinases [MMP-2and-9] and their natural inhibitors as prognostic indicators in solid cancers: Biochimie. 2005;87:287-97.

8. Laing J, Rew D, Wilson G. Cell kinetics of human solid tumours. BJR supplement/BIR. 1992;24:163.

9. Vaisanen A, Kuvaja P, Kallioinen M, et al. A prognostic index in skin melanoma through the combination of matrix metalloproteinase-2, Ki67, and p53. Human Pathol. 2011;42:1103-11.

10. Ramsden A, Grover R, Chana J, et al. A prospective analysis of c-myc oncoprotein levels as a prognostic marker in malignant melanoma. J Plast Reconstruct Aesth Surg .2007;60:626-30.

11. Väisänen AH, Kallioinen M, Turpeenniemi-Hujanen T. Comparison of the prognostic value of matrix metalloproteinases 2 and 9 in cutaneous melanoma. Human Pathol. 2008;39:377-85.

12. Ross D, Laing JHE, Sanders R, et al. Long term follow-up of c-myc, p53 and proliferation measurements in malignant melanoma. Eur J Surgl Oncol. 2006;32:80-4.

13. Chapman PB, Hauschild A, Robert C, et al. Improved survival with vemurafenib in melanoma with BRAF V600E mutation. N Eng J Med. 2011;364:2507-6. 